\title{
AN INTERPRETIVE PERSPECTIVE ON THE ROLE OF Strategic CONTROL IN TRIgGering STRATEgiC CHANGE
}

\author{
Scott D. Julian \\ Saginaw Valley State University \\ University Center, MI \\ Elton Scifres \\ Stephen F. Austin State University \\ Nacogdoches, TX
}

\begin{abstract}
Rapidly changing environments press organizations to respond in an appropriate and timely fashion. Strategic control plays an important role in this adaptation process through its identification and interpretation of "change triggers" - critical events in the external environment that mandate an organization's response. We argue that giving more prominent place to data interpretation in the strategic control process facilitates the identification of factors that trigger change. We build a conceptual model around a three-step process of scanning/monitoring, data interpretation, and response combined with three different levels of strategic control (strategic surveillance, premise monitoring, and implementation control). The model assists managers by highlighting the factors that can cause Type II errors (not changing when change is required) and provides researchers with directions for future inquiry.
\end{abstract}

\section{Introduction}

Business leaders face an unprecedented level of market turmoil and dynamism. The globalization of markets, the liberalization of the former East-bloc economies, the increasing diversity of the workforce, and the rising ubiquity of the Internet are only a few of the factors driving rapid change. Such changes mandate responses on the part of individual businesses but this begs several questions of managers: do we need to respond, when should we respond, and what should be the nature of our response? While managers have faced similar questions in the past, there is growing agreement that the pace of change has quickened: managers have less time to respond to change.

Change triggers are events in the external environment of such importance and magnitude that they mandate an organization's response (Napster had no choice but to respond to court rulings that it had violated copyright protection). These change triggers play an important role in strategic control. Rajagopalan and Spreitzer (1997) identified triggering strategic change as a "key unresolved issue" in the academic literature (p. 72), and called for more research into this 
important area. Strategic changes are adjustments an organization makes to better align itself with its environment, improving the likelihood of successful strategy implementation. One reason triggering change remains unresolved is that the literature cited by these authors has generally not employed frameworks or concepts from research on strategic control. The strategic control literature has more directly addressed this issue of triggering change (Muralidharan, 1997; Picken \& Dess, 1997; Preble, 1992). For example, Schreyogg and Steinmann (1987) identified three different ways in which the need for strategic changes can be identified: tracking performance indicators; challenging the validity of crucial assumptions underlying a particular strategy; and identifying emerging issues through macro-environmental scanning.

We assert that the value of strategic control research in addressing the triggering of change can be enhanced by more fully integrating data interpretation into models of strategic control. While Rajagopalan and Spreitzer (1997) incorporated managerial cognition and data interpretation into their multi-lens framework of strategic change, these concepts have generally been overlooked in strategic control studies (Fiegener, 1994, 1997; and Lorange, et al., 1986 are notable exceptions). Currently, no research has systematically applied cognitive and interpretive concepts to strategic control, nor has it attempted to present strategic control as essentially a data interpretation activity. We, therefore, consider strategic control from an interpretation perspective and then apply this interpretive framework to the issue of the timely triggering of strategic change.

\section{Model of the Strategic Control Process}

Strategic control involves the monitoring and evaluation of plans, activities, and results with a view toward future action (Goold \& Quinn, 1990; Preble, 1992), providing a "warning bell" through diagnosis of data (Quinn, 1996). The clear intent of strategic control is the triggering of appropriate changes in strategy, be they either tactical adjustments or strategic reorientations (Lorange, et al., 1986; Lorange, 1988). This set of rational procedures strongly reflects what Rajagopalan and Spreitzer (1997) termed the "rational lens" perspective of strategic change. Our working definition of strategic control, then, is "a set of monitoring procedures that provide information for triggering strategy modification."

One could argue that identifying and interpreting change triggers is equivalent to testing hypotheses: the researcher faces the risk of both Type I and Type II errors (Boyd, Dess \& Rasheed, 1993). An effective strategic control system is one that triggers the appropriate response at the appropriate time, avoiding both types of errors. From a strategic control perspective, a Type I error occurs when the situation does not require a tactical or strategic change yet managers misread signals and assume that such change is required. A Type II error occurs when the organization is too inert: managers fail to recognize the need for strategic change in situations where it actually exists. While Type I errors are certainly possible, 
given the current dynamic business environment, inertia-like Type II errors are the more likely problem.

In statistics, Type II errors can be caused by a variety of factors. The sample size may too small to provide enough information or an adequate level of statistical power. We consider this a "data" issue. In strategic control, small sample size problems correspond to having an inadequate amount of the correct type of data. A given strategic control system may collect and disseminate a large amount of data, but if it is not appropriate data then an organization's decision-makers suffer the equivalent of a small sample size. Alternatively, alpha, the point at which managers reject the null hypothesis that no change is required (thus, triggering change), may be set too low. We consider this a "decision" issue. Various factors both inside and outside of an organization can affect trigger sensitivity, related to the setting of alpha, or the point at which managers decide to reject the null hypothesis and trigger strategic change. We suggest that the structure of scanning and monitoring activities can cause data problems and that an organization's external and internal contexts can cause decision problems. Such unrecognized data shortcomings and unintended sensitivity shifts can increase the risk of Type 11 errors whereby managers fail to trigger timely and appropriate change.

\section{Model Summary}

To trigger either tactical adjustments or strategic reorientations, decisionmakers must collect data, make a determination as to its meaning through comparison to preexisting standards or aspirations, and then respond in some way. It is, in other words, inherently a data interpretation process. This interpretation is more than simple analysis of data. It is an elaborate sense-making activity whereby organizational actors try to give meaning to complex, and possibly unordered, data (Daft \& Weick, 1984; Weick, 1995). Through formal analysis, managerial judgment, intuition, and social information processing, organizational members make sense of the world around them.

The strategic control model in Figure 1 is based on this interpretive view of triggering strategic change and identifies a variety of factors potentially affecting inertia-like, Type II errors. We present strategic control as an interpretation process having three stages: scanning/monitoring; analysis/interpretation; and response (Daft \& Weick, 1984; Weick, 1995). Scanning and/or monitoring of various factors in the external and internal environments is the first of these three. In the next stage, data analysis and interpretation, organizational members imbue data with meaning. Depending on the results of the second stage, the organization takes some kind of action, or responds. In the content dimension of Figure 1, we represent strategic control as comprising three separate activities: strategic surveillance; premise control; and implementation control (Muralidharan, 1997; Preble, 1992; Schreyogg \& Steinmann, 1987). This multi-faceted, and multi-level, approach captures the variety of tasks strategic control must involve given today's increasingly demanding business environments. Additionally, these different tasks represent three different 
ways that strategic change can be triggered, each involving a different focus of attention and process.

Figure 1

\section{Model of the Strategic Control Process}

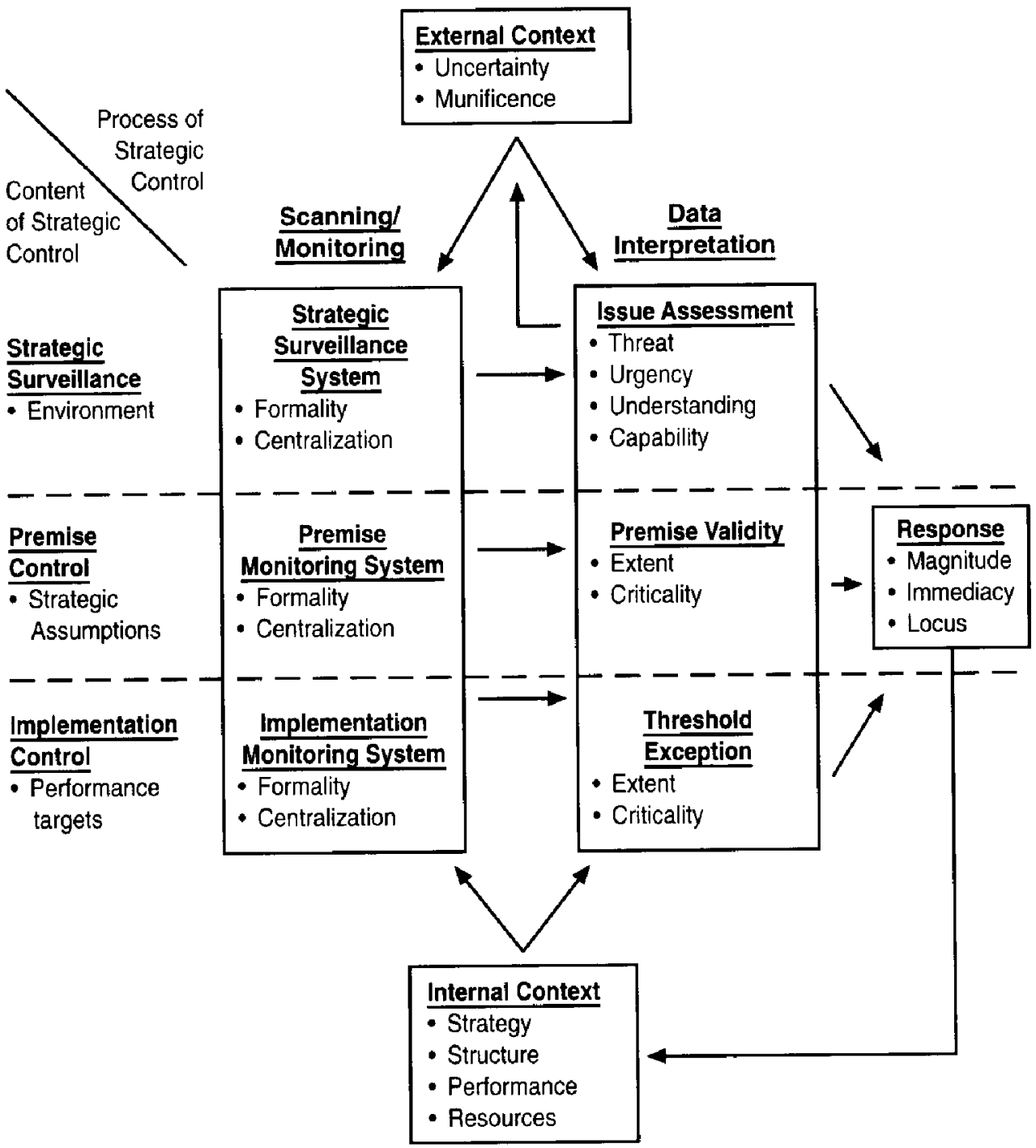

Strategic surveillance is broad-based monitoring of the environment whereby the organization interprets, analyzes, and responds to strategic issues (Muralidharan, 1997; Preble, 1992; Schreyogg \& Steinmann, 1987). Since the process of strategy planning and implementation normally tends to narrow the scope of awareness to a relatively few number of factors (Miller, 1993), organizations need to broaden their scope of attention. Strategic surveillance helps identify trends and developments emerging from areas not previously identified 
as important (Preble, 1992). Decision makers package unordered data and stimuli from the environment into coherent and related sets called "issues" that they then can analyze and assess as to their potential impact (Martins \& Kambil, 1999; Sharma, 2000).

Premise control, the second strategic control component, concerns the underlying strategic assumptions made in earlier planning efforts regarding internal and external factors (Lampel \& Shamsie, 2000; Preble, 1992). During strategy formulation, executives identify critical assumptions underlying their strategy (Lorange, 1988). Once executives identify these assumptions, effective organizations design and implement monitoring systems to ascertain their continued validity. The strength of premise control is its feedforward nature, since it is able to identify potential problems while they are still minor and before they affect an organization's performance (Schreyogg \& Steinmann, 1987).

Implementation control, the third strategic control component, requires monitoring strategy implementation performance, usually through milestones, critical success factors, budgets and thresholds, and takes the form of classic feedback control (Preble, 1992; Schreyogg \& Steinmann, 1987). Its purpose is to aid managers in making a determination, based on strategy implementation, whether to alter the basic strategic direction. Managers identify important milestones and set strategic thresholds to assist them in knowing when they should consider a change in strategy (Muralidharan, 1997).

Thus, as indicated above, strategic change can be triggered in a number of ways. Concerning strategic surveillance, some environmental changes have sudden and immediate impact. The discovery of mad cow disease in the UK in 2000 depressed beef sales in Europe requiring fast food firms to promote alternative menus of chicken or fish. Other environmental changes like deregulation emerge more slowly and have predictable consequences: increased competition, pricing pressures, and increased innovation to name but a few. Astute managers respond forcefully to such change triggers. When the FCC decreed that telephone companies could transmit video signals over phone lines, many cable companies recognized the clear and immediate threat this created. The response of these firms was to merge or partner with telephone companies to reduce the effects of direct competition. At a more subtle level, slow and incremental changes in an environment can accumulate until they reach or pass a strategic change trigger. This was certainly the case of the fast food industry in the mid1990s. Food researchers had discovered that as people age, their taste buds begin to die; older consumers required more flavor in order to receive the same positive taste experience they had as youth (Taylor, et al., 2001). McDonald's, recognizing a decline in share as its customer base aged, responded by creating the "Arch Deluxe" and positioning it as the hamburger for adults.

Regarding premise control and change triggers, managers will have identified specific assumptions, the falsehood of which would indicate the need for a strategic change. For example, GM had assumed that its Saturn division could attain a certain level of costs and when it became apparent that it could not, GM's 
executives altered its "Saturn strategy" (Muralidharan, 1997). Strategic change can also be triggered by the failure to attain certain levels of anticipated performance, and this occurs through the process of implementation control. The lagging far below aspirations of financial performance and market share indicators, for example, will likely generate some form of strategy modification in order to correct the situation. In other cases, firms may recognize that they are in a unique resource position that allows them to undertake dramatic new strategies. Such was the case of $\mathrm{AOL}$, which used its inflated stock price at the end of the millennium to acquire Time Warner (Drummond, 2000). In some instances, it may seem that strategic change has some other precipitating event, such as a new CEO (think of Jack Welch at General Electric, for example, and the strategic changes that ensued). The changes such an individual initiates, however, are probably based on different interpretations of issues, divergent strategic assumptions, or higher aspiration levels, relating to the three strategic control components.

\section{Data Interpretation}

Interpretation occurs in each of the three content components of the strategic control process, although in some cases it would seem that analysis would be cut-and-dried: either a milestone was missed or made, a threshold exceeded or not. In practice, managers frequently use discretion in such situations that may require their judgment (Finkelstein \& Hambrick, 1996).

Researchers in strategic issue management have extensively explored the interpretation of important developments and trends identified in strategic surveillance. Once organizational decision makers have assembled a confluence of related stimuli into a strategic issue (Dutton, 1993), they make various assessments and categorizations. For example, decision-makers may assess the issue as an opportunity or a threat, influencing the organization's response (Denison, et al., 1996). They also assess the issue's urgency, the organization's understanding of the issue, and its capability to respond (Dutton \& Duncan, 1987; Ginsberg \& Venkatraman, 1995).

Data interpretation in premise control concerns the validity of premises that underlie the current strategy. Data relating to this assessment addresses stakeholder behavior and may be equivocal, given the qualitative nature of many of these assumptions (Preble, 1992). Decision-makers must make judgments pertaining to the degree of violation and the criticality of that particular assumption. Although all the assumptions by definition are "critical," some premises may be more important than others in the eyes of decision-makers, based on changing factors in the external and internal contexts (discussed later) and their potential strategic consequences.

Data interpretation for implementation control involves assessing whether an organization has missed milestones or exceeded thresholds. An organization's executives will have set these performance targets and identified critical success factors earlier during strategic planning (Muralidharan, 1997). While deciding 
if any negative variances or missed targets have occurred may be a relatively simple task, deciding what this data might mean may not. In some cases, managers properly resist alterations to strategy in order to avoid a Type I error. Decision-makers must assess the extent and criticality of exceptions, an interpretational process heavily dependent on what they might consider extenuating circumstances.

\section{Organizational Responses}

The factors affecting data interpretation are important because of the effect interpretation has on organizational responses. Type II errors are a concern in that they result in organizational responses that are either too slow in coming or of too little magnitude to adequately deal with problems at hand. We now briefly examine the effects of interpretation on both response and the internal context.

Data interpretation can influence the kinds of responses organizations take (e.g., Ginsberg \& Venkatraman, 1995; Thomas, Clark, \& Gioia, 1993). We show this in Figure 1 by the three arrows pointing from the data interpretation stage to response, each arrow representing interpretations relating to a different strategic control content component. Research examining organizational responses to various issues and events has made extensive use of three particular dimensions: magnitude, the size of response; immediacy, the rapidity of response; and locus, the extent to which the response is outward- or inward-directed (Ferrier, Smith, \& Grimm, 1999; Smith \& Grimm, 1991; Thomas, et al., 1993).

Strategic surveillance responses depend on managerial assessments of issue threat, urgency, understanding, and capability. For example, the more urgent an issue, the greater the extent of response to it (Ginsberg \& Vekatraman, 1995). Responses relating to premise control depend upon assessment of premise validity. If decision-makers find strategic assumptions to be valid, a likely response will be to do nothing. If decision-makers find strategic assumptions to be invalid, the response would depend upon assumption criticality and the extent of assumption violation. Responses relating to implementation control are similar to those corresponding to premise control.

Once an organization responds, the internal context of the firm changes since responses primarily consist of manipulating strategy, structure, and resources; factors often assumed to be under decision makers' control. These responses can indirectly affect the manner in which an organization carries out strategic control, the types of data interpretations made, or even perceptions of the external environment, depending upon the nature of the responses. These changes can then influence the kinds of responses made in the future as part of the strategic control process.

In the preceding sections we have outlined the basic elements of our strategic control model. In the following sections. we attempt to explore the influence of various contextual factors on organizational response. Specifically we shall offer a series of propositions that explore the influence of 
scanning/monitoring system characteristics, the external context, and the internal context.

\section{The Influence of Scanning/Monitoring System Characteristics}

The structure of the scanning/monitoring process and implementation systems can also affect data interpretation, and hence, the likelihood of Type II nonresponse errors. Figure 1 indicates this by the arrows pointing from the various systems in the scanning/monitoring stage to the data interpretation stage.

Research has suggested that process formality and centralization are two important aspects of scanning/monitoring (Dutton, 1993; Sutcliffe, 1994). Process formality is the rationalization of strategic control by standardized and routinized procedures and data sources, such as market studies, published statistics, budgets, and audits (Band \& Scanlan, 1995; Mintzberg, 1994, Picken \& Dess, 1997). Centralization refers to the degree to which individuals at higher levels in the organization's hierarchy perform scanning/monitoring activities (Sutcliffe, 1994). Our concern here is to identify the likely effects of formality and centralization on data interpretation and trigger sensitivity. To this end, we offer the following series of propositions.

Formality in Strategic Surveillance. Formality in environmental scanning can influence assessments of strategic issues. It is generally not possible, a priori, to know what developments in, or sectors of, an environment will be the source of new critical contingencies. Formalized strategic issue diagnosis prespecifies where to scan for strategic issues and this limits cognitive effort and restricts the search for information (Dutton, 1993; Starbuck \& Milliken, 1988). Beyond this, such "automatic" information processing often leads to the use of ready made, though perhaps inappropriate, categories (Dutton, 1993). Inertia and lethargy in interpretation caused by formalization reduces awareness of, and responsiveness to, newly emerging issues. Such routinization also leads, over time, to monitoring a more narrow set of environmental factors (Miller, 1993). Although he recognized some benefits of formalization, Mintzberg (1994) criticized formal systems and the hard data they often produce. He argued that hard data lacks richness, is too aggregated, is often late, and may not always be reliable (pp. 259-264). Those depending on such systems may fail to receive the proper amount of the right kind of data. A formal scanning system will thus likely focus attention in the wrong direction and lead to the under collection of the correct type of data, corresponding to a low sample size problem.

The experiences of IBM exemplify the problems with a high level of formality in strategic surveillance (Loomis, 1993). IBM instituted a mass of bureaucratic procedures to gain control of the confusion surrounding its introduction of the 360 mainframe computer in the mid-1960s. Formalization proved less useful when applied, as it eventually was, to the collection and assessment of environmental data. Focus on the process of analysis and decision making, rather than the meaning of the data itself, caused them to react slowly to emerg- 
ing issues such as RISC technology. Based on the foregoing, we posit the following proposition.

\section{Proposition 1: Formal strategic surveillance systems increase} the chance of Type II errors.

Formality in Premise and Implementation Monitoring. Formalization should have an effect on trigger sensitivity relating to premise and implementation monitoring. System formality routinizes the collection and reporting of data, thus assuring its timely availability. Formalization is effective in focusing attention, establishing participation, and ordering data (Mintzberg, 1994), all useful functions in performance and premise monitoring. Schreyogg and Steinmann (1987) suggested that formalization be high to moderate in premise and implementation monitoring since prespecification of the factors on which managers should focus their attention is possible in these forms of strategic control.

Decision makers often do not detect poor performance or premise invalidity early enough to implement timely and effective responses (Weitzel \& Jonsson, 1989), and in part we attribute such Type II errors to insufficient amounts of data. Where the process of monitoring performance and premises is ad hoc and informal, decision makers may fail to receive an adequate amount of timely data: a low sample size problem. Fiegener (1997) found that perceptions of strategic control effectiveness increased as system formality increased. The implication here is that formality increases trigger sensitivity level by increasing available data. Thus, we posit the following proposition.

\section{Proposition 2: Formal premise and implementation monitor-} ing systems decrease the likelihood of Type II errors.

Centralization in Strategic Surveillance and Premise Monitoring. The effect of centralization on strategic surveillance and premise monitoring trigger sensitivity is influenced by the need for those so engaged to have understanding of the larger strategic context of the firm. When scanning is decentralized, for example, lower level personnel often will not know the relevance of information to which they have access or will fail to communicate it adequately to their superiors (Shank, et al., 1988; Sutcliffe, 1994). Individuals at higher levels in the firm's hierarchy are more likely to possess the necessary intimate knowledge of the strategic posture and its underlying assumptions, so they are the ones best suited for strategic surveillance and premise control. Through more immediate comprehension of the significance of information gathered through strategic surveillance and premise control activities, centralization of these activities should lead to a reduced likelihood of Type II errors. This logic leads to the following proposition. 
Proposition 3: Centralized strategic surveillance and premise monitoring systems decrease the likelihood of Type II errors.

Centralization in Implementation Monitoring. Schreyogg and Steinmann (1987) recommended that centralization in implementation monitoring be moderate to low. Lower level managers have immediate access to data addressing strategy implementation and are likely to be well aware of the importance of the pertinent milestones and thresholds. Delays and distortions are often involved with communicating implementation control data up the corporate hierarchy and then communicating back higher-level manager's responses to that data, known as the serial transmission effect. Centralization can also lead to executive complacency since they think they have higher levels of understanding due to their close involvement with the data, when in fact this data may be distorted (Mintzberg, 1994). Thus, centralization can lead to higher risks of Type Il errors through both reducing the amount of relevant data and lowering alpha, the point at which managers recognize the need to change. Therefore, we suggest the following proposition.

\section{Proposition 4: Centralized implementation monitoring sys- tems increase the likelihood of Type II errors.}

\section{The External Context and its Influence}

The interpretation process is subject to various contextual forces (Dutton \& Ottensmeyer, 1987; Sharma, et al., 1999). According to our interpretive framework, both the organizational and the environmental contexts directly influence the strategic control process at the scanning/monitoring and the data interpretation stages. These contextual factors affect the risk of Type II errors primarily through low alpha problems, or reduced trigger sensitivity.

The recent experiences of firms in the recording industry illustrate how external environmental shifts can increase the chances of Type II errors. Startup firms, such as Napster, saw the potential of the internet as a new distribution system more convenient and responsive to consumers' needs and interests. Established recording firms, however, were slow to react to changes brought about by the World Wide Web, changes that could have completely bypassed the current system based on physical distribution and decentralized retailing. As it turns out, some firms, such as Bertelsmann, are belatedly exploring new options made possible by the Internet (Leonard, 2001). Had the courts not severely restricted this new distribution model, firms in the recording industry could have faced an uncertain and threatening future.

Generalizing from this example, we suggest that the external context, composed of organizational perceptions of the environment, can influence both scanning/monitoring and interpretation, as shown in Figure 1. We focus on the direct effect of the external context on interpretation, though we recognize the external context can indirectly affect interpretation via the structure of and 
emphasis on scanning/monitoring. Two primary dimensions used to measure the external environment are uncertainty and munificence. Uncertainty is the degree of unpredictability in an environment and consists of dynamism (the rate of change) and complexity (the number of factors that must be considered to understand an environment) (Clark, et al., 1994; Sharfman \& Dean, 1991). Munificence is the abundance of resources in an environment needed by organizations operating within it (Castrogiovanni, 1991; McArthur \& Nystrom, 1991). The influence of these environmental dimensions is explored in the following propositions.

Increasing Environmental Uncertainty. Environmental perceptions developed over time form a cognitive filter molding and influencing subsequent decision-maker understanding of data gathered during scanning/monitoring (Boyd, Dess, \& Rasheed, 1993). Decision-makers who have operated in a relatively placid and simple environment, where change occurred slowly and predictably and the number of factors to be tracked was low, would tend to think there is plenty of time to deal with an emerging strategic issue, premise invalidity, or performance threshold exception. This view would seem plausible since there has always been time to adequately respond in the past and because the relative simplicity of the external environment lent itself to easy and rapid analysis. Thus, previous experience in a certain environment would tend to increase the risk of Type II errors by lowered trigger sensitivity, particularly when environmental dynamism and complexity have recently increased. On the other hand, if dynamism has recently slowed, decision-makers might be more prone to Type I errors: changing when it is not required. Clearly, given the increasing rates of change in business in recent years, the former situation requires greater managerial attention in strategic control than the latter. Thus, we posit the following proposition.

\section{Proposition 5: The likelihood of Type II errors increases when organizational environments shift from certain (placid and simple) to uncertain (dynamic and complex).}

Decreasing Environmental Munificence. Environmental munificence can affect interpretations resulting from premise monitoring and implementation control. Munificent environments have capacity and opportunity for growth (Castrogiovanni, 1991) and are very forgiving in that survival and profitability are relatively easy. Decision makers having previously operated in a munificent environment would be less likely to view invalidation of a premise or violation of a performance threshold as a critical or alarming event, given the "extenuating circumstances" of the bountiful external context. Hence, Type II errors via lowered trigger sensitivity are made more likely by previous involvement with munificent environments, particularly when these environments have become 
more hostile. Decision-makers in environments of increasing munificence, however, might be vulnerable to Type I errors, as above. Given that competition within many industry environments seems to generally be on the rise, however, the former situation is likely to require a greater amount of managerial attention than the latter. We, therefore, suggest the following proposition.

Proposition 6: The likelihood of Type II errors increase when an organization's environment shifts from munificent to hostile.

\section{The Internal Context and its Influence}

The internal context, which includes strategy, structure, performance, and resources, also influences scanning/monitoring and interpretation activities as shown in Figure 1. Again, our focus is on the impact of the internal context on interpretation, though an indirect effect mediated by scanning/monitoring can also exist. The following discussion explores the influence of strategy and performance on data interpretation and response.

Defender-type Strategies. Using the Prospector/Defender strategy typology as an example of the effect of internal context (Ketchen, et al., 1993; Miles \& Snow, 1978), organizations with aggressive, prospector-type strategies are likely to differ from Defenders in their interpretation of strategic issues. For example, Prospectors are likely to rate highly their organizational capability in relation to emerging issues. Since Prospectors seek out change, and indeed, are often the originators of it, decision makers within these organizations are likely to feel very comfortable regarding their ability to deal with change, even if they do not control it. Defenders avoid change, however, and this lack of comfort with change would lead to much lower assessments regarding capability to deal with new strategic issues. Decision makers in Defender firms are more focused on a narrow market niche, selected for its stability. Such organizations are not structured for change (Fox-Wolfgram, et al., 1998), nor are they anticipating the need to change. Because of this, such decision-makers in Defenders firms may not view newly emerging strategic issues, for example, as very relevant for their organization. Such lowering of trigger sensitivity increases the risk of Type II errors for Defender firms.

Enron is a good example of how firms with a Prospector-type strategy have a lower risk of Type Il errors. This firm is well known for its aggressive and innovative market moves involving not only energy but also in the trading of commodities. Enron recognized the significance of the Internet in relation to its gas trading business and in a matter of months got a website up and running whereon clients could trade natural gas (Hamel, 2000). Based on the foregoing, we posit the following proposition. 
Strong Organizational Performance. Organizational performance, another internal context dimension, can also affect data interpretations. The risk-return paradox suggests that poorly performing firms are risk seeking while higher performing firms are risk averse (Feigenbaum \& Thomas, 1988). Our model suggests that interpretation mediates this linkage. High performance levels result in an interpretation context where managers are more likely to assess performance threshold exceptions, for example, as being of low criticality. Since performance is strong, managers may be complacent and satisfied (Audia, et al., 2000), perceiving a larger margin for error than may actually exist, in effect lowering their trigger sensitivity.

Digital Equipment Corporation enjoyed strong performance in the 1970s through its reputation for building high quality, reliable computers. This success, however, resulted in a lack of sensitivity to the emerging trend of smaller size and user-friendliness in technology (Miller, 1993). Their entry into the personal computer market failed to incorporate these new customer demands and was a dismal failure. Similar failures in commercialization led to the eventual loss of billions of dollars in the early 1990s. Consistent with this logic and example, we posit the following proposition.

Proposition 8: The likelihood of Type II errors is higher when organizational performance is strong.

Table 1 summarizes these eight propositions. In addition, the model includes links to other relationships. Since these are neither of direct nor central importance to the triggering of strategic change, we do not discuss them here. We include them so as not to imply that these linkages do not exist.

Table 1

Factors Affecting the Likelihood of Type II Errors

\begin{tabular}{clc}
\hline Proposition & Factors & Effect on Type II Error \\
\hline 1 & Strategic Surveillance Formality & Increase \\
2 & Premise Monitoring Formality & Decrease \\
3 & Strategic Surveillance \& Premise Monitoring Centralization & Decrease \\
4 & Implementation Monitoring Centralization & Increase \\
5 & Increasing Environmental Uncertainty & Increase \\
6 & Decreasing Environmental Munificence & Increase \\
7 & Defender-type Strategies & Increase \\
8 & Strong Organizational Performance & Increase \\
\hline
\end{tabular}




\section{Summary and Implications for Future Research}

Through its scanning and interpretation components, strategic control represents a primary driver of strategic change. The increasingly discontinuous nature of today's business environments makes the discovery and interpretation of change triggers essential to proper strategic reorientations or tactical adjustments. Thus, strategic control has an essential role to play in avoiding Type II errors: failing to change when change is required. By more fully integrating the concept of data interpretation into strategic control, one can facilitate the identification of the factors affecting trigger sensitivity and can more easily discern their likely effects. Previous research has not sufficiently incorporated interpretation into conceptualizations of strategic control; this paper makes progress toward that end. Rajagopalan and Spreitzer (1997) recommended that researchers employ a variety of lenses, such as rational, cognitive, and learning. Our strategic control framework employs all three perspectives: the rational approach of traditional strategic control; the cognitive approach that considers strategic control as a data interpretation activity; and the learning approach of the feedback loops from response to internal context and data interpretation to external environment. By using multiple viewpoints, our interpretive framework more effectively illustrates the pattern of influences operating on strategic control and affecting the risks of inertia-like, Type II errors.

Using our interpretive framework, practitioners can be more aware of the variety of factors that influence the operation of their strategic control system and therefore their company. Timely and appropriate strategic change is more likely to occur when managers design and operate strategic control systems with these factors in mind. Managers should exercise their choices regarding these structural characteristics while being mindful that formality and centralization can make Type II errors more or less likely, depending upon the type of strategic control activity. In addition, the framework suggests that trigger errors of either type are more likely to occur when there has been a dramatic shift in the external environment. Given this increased potential for Type I and Type II errors, managers could adjust the control system structure to compensate for these tendencies.

Testing our eight propositions would involve measuring both the dependent (Type II errors) and independent (structure, context) variables. The challenge in measuring the dependent variable is to identify situations where not only did an organization fail to initiate change, but to also specify when such changes were actually necessary. Through the use of archival data (as done, for example, in Ferrier, et al. [1999]), after-the-fact determination of whether a change was needed or not could occur through the use of a panel of either industry and/or academic experts. If a change in strategy was required but none initiated, for example, this situation could be coded as a Type II error. Consultation of annual reports would enable measurement of some internal context variables (performance, for example; or certain indicators of strategy); whereas reference to 
secondary data relating to industry conditions would enable measurement of the external context variables (uncertainty and munificence). Measuring strategic control system structure, however, would be more difficult and could require the use of retrospective accounts. A possible and preliminary alternative to this would be to utilize a business simulation to generate the needed data, as done in Audia, et al. (2000). In such a case, situational generalizability would have to be traded off against data availability and validity. Given that the dependent variable would have two categories (change required, did change; change required, did not change), the data could be analyzed by using logistic regression.

Our interpretive strategic control model highlights some important areas for future research. For example, does the external context influence strategic surveillance activities more than it affects premise and implementation monitoring? Does it influence them in different ways? Does the internal context influence each component of control or the emphasis placed on each component? Other issues relate to strategic control system performance (Fiegener, 1994, 1997), and several questions appear particularly relevant. Do organizations with certain types strategic control systems outperform those that do not have them? Which component of strategic control has the most significant effect on performance and what environmental and organizational characteristics moderate this relationship?

The interpretive model also captures the iterative and dynamic nature of strategic control, providing a useful background for viewing strategic control activities as complex adaptive systems (Anderson, 1999). For example, the structure of an organization's scanning/monitoring systems influences interpretation, which influences organizational responses, which change the internal context and thus the scanning/monitoring system. Being complex and adaptive, the state of any strategic control system at time $t+1$ is a function of its state at time $t$. Thus, it is entirely likely that slight differences in initial conditions can, over time and through continuous iteration, be magnified orders of magnitude by self-reinforcing and positive feedback loops. Our model fits well within the burgeoning research on organizations as complex adaptive systems. Future research along these lines using our interpretive model as a template might prove fruitful.

\section{References}

Anderson, P. (1999). Complexity theory and organization science. Organization Science, $10,216-232$.

Audia, P.G., Locke, E.A., \& Smith, K.G. (2000). The paradox of success: An archival and a laboratory study of strategic persistence following radical environmental change. Academy of Management Journal, 42, 837-853.

Band, D.C., \& Scanlan, G. (1995). Strategic control through core competencies. Long Range Planning, 28(2), 102-114. 
Boyd, B.K., Dess, G.G., \& Rasheed, A.M.A. (1993). Divergence between archival and perceptual measures of the environment: Causes and consequences. Academy of Management Review, 18, 204-226.

Castrogiovanni, G.J. (1991). Environmental munificence: A theoretical assessment. Academy of Management Review, 16, 542-564.

Clark, T., Varadrajan, P.R., \& Pride, W.M. (1994). Environmental management: The construct and research propositions. Journal of Business Research, 29, 23-38.

Daft, R.L, \& Weick, K.E. (1984). Toward a model of organizations as interpretation systems. Academy of Management Review, 9, 284-295.

Denison, D.R., Dutton, J.E., Kahn, J.A., \& Hart, S.L. (1996). Organization context and the interpretation of strategic issues: A note on CEO's interpretations of foreign investment. Journal of Management Studies, 33, 453-474.

Drummond, M. (2000). Big music fights back. Business 2.0, December 12, 154.

Dutton, J.E. (1993). Interpretations on automatic: A different view of strategic issue diagnosis. Journal of Management Studies. 30, 339-357.

Dutton, J.E., \& Duncan, R.B. (1987). The creation of momentum for change through the process of strategic issue diagnosis. Strategic Management Journal, 8, 279-295.

Dutton, J.E., \& Ottensmeyer, E. (1987). Strategic issue management systems: Forms, functions, and contexts. Academy of Management Review, 12, 355-36.5.

Ferrier, W.J., Smith, K.G., \& Grimm, C.M. (1999). The role of competitive action in market share erosion and industry dethronement: A study of leaders and challengers. Academy of Management Journal, 42, 372-388.

Fiegenbaum, A., \& Thomas, H. (1988). Attitudes toward risk and the risk-return paradox: Prospect theory explanations. Academy of Management Journal, 31, 85-106.

Fiegener, M.K. (1994). Matching business level strategic controls to strategy: Impact on control system effectiveness. Journal of Applied Business Research, 10, 25-34.

Fiegener, M.K. (1997). The control of strategy in dynamic versus stable environments. Journal of Managerial Issues, 9(1), 72-85.

Finkelstein, S., \& Hambrick, D.C. (1996). Strategic leadership: Top executives and their effect on organizations. Minneapolis/St. Paul: West Publishing.

Fox-Wolfgramm, S.J., Boal, K., \& Hunt, J.G. (1998). Organizational adaptation to institutional change: A comparative study of first-order change in prospector and defender banks. Administrative Science Quarterly, 43, 87-126. 
Ginsberg, A., \& Venkatraman, N. (1995). Institutional initiatives for technological change: From issue interpretation to strategic choice. Organization Studies, 16, 425-488.

Goold, M., \& Quinn, J.J. (1990). The paradox of strategic controls. Strategic Management Journal, 11, 43-57.

Hamel, G. (2000). Driving grassroots growth. Fortune, 142(5), 173-187.

Ketchen, D.J., Jr., Thomas, J.B., \& Snow, C.C. (1993). Organizational configurations and performance: A comparison of theoretical approaches. Academy of Management Journal, 36, 1278-1313.

Lampel, J., \& Shamsie, J. (2000). Probing the unobtrusive link: Dominant logic and the design of joint ventures at G.E. Strategic Management Journal, 21, 593-602.

Leonard, D. (2001). The music men are out of tune. Fortune, 143(12), 144-148.

Loomis, C. (1993). Dinosaurs? Fortune, 127(9), 36+.

Lorange, P. (1988). Monitoring strategic process and ad hoc strategic modification. In J. Grant (Ed.), Strategic management frontiers: 261-285. Greenwich, CT: JAI Press.

Lorange, P., Scott-Morton, M.F., \& Ghoshal, S. (1986). Strategic Control Systems. St. Paul, MN: West.

McArthur, A.W., \& Nystrom, P.C. (1991). Environmental dynamism, complexity, and munificence as moderators of strategy-performance relationships. Journal of Business Research, 23, 349-361.

Martin, L., \& Kambil, A. (1999), Looking back and thinking ahead: Effects of prior success on managers' interpretations of new information technologies. Academy of Management Journal, 42, 652-661.

Miles, R.E., \& Snow, C.C. (1978). Organizational strategy, structure, and process. New York: McGraw-Hill.

Miller, D. (1993). The architecture of simplicity. Academy of Management Review, 18: 116-138.

Mintzberg, H. (1994). The rise and fall of strategic planning: Reconceiving roles for planning, plans, planners. New York: The Free Press.

Muralidharan, R. (1997). Strategic control for fast moving markets: Updating the strategy and monitoring performance. Long Range Planning, 30(1), 64-73.

Picken, J.C., \& Dess, G.G. (1997). Out of (strategic) control. Organizational Dynamics, $26(1), 35-48$. 
Preble, J.F. (1992). Toward a comprehensive system of strategic control. Journal of Management Studies, 29, 391-409.

Quinn, J.J. (1996). The role of "good conversation" in strategic control. Journal of Management Studies, 33, 381-394.

Rajagopalan, N., \& Spreitzer, G.M. (1997). Toward a theory of strategic change: A multi-lens perspective and integrative framework. Academy of Management Review, 22, 48-79.

Schreyogg, G., \& Steinmann, H. (1987). Strategic control: A new perspective. Academy of Management Review, 12, 91-103.

Shank, M.E., Zeithaml, C.P., Blackburn, R.S., \& Boynton, A.C. (1988). Predictors of top management team environmental perception accuracy: A model and propositions. Academy of Management Proceedings: 37-41.

Sharfman, M.P., \& Dean, J.W., Jr. (1991). Conceptualizing and measuring the organizational environment: A multidimensional approach. Journal of Management, 17, 681-700.

Sharma, S., Pablo, \& A., Vredenburg, H. (1999). Corporate environmental responsiveness strategies: The importance of issue interpretation and organizational context. The Journal of Applied Behavioral Science, 35, 87-108.

Sharma, S. (2000). Managerial interpretations and organizational context as predictors of corporate choice of environmental strategy. Academy of Management Journal, $43,681-697$.

Smith, K.G., \& Grimm, C.M. (1991). A communication-information model of competitive response timing. Journal of Management, 17, 5-23.

Starbuck, W.H. \& Milliken, F.J. (1988). Executives' perceptual filters: What they notice and how they make sense of it. In D. C. Hambrick (Ed.), The executive effect: Concepts and methods of studying top managers: $35-66$. Greenwich, CT: JAI Press.

Sutcliffe, K.M. (1994). What executives notice: Accurate perceptions in top management teams. Academy of Management Journal, 37, 1360-1378.

Taylor, M.L., Puia, G.M., Ramaya, K., and Genglebach, M. (2001). Outback goes international, in Hitt, Ireland, Hoskission, Strategic Management, (4th ed.). Cincinnati: South-Western Publishing Co.

Thomas, J.B., Clark, S.M., \& Gioia, D.A. (1993). Strategic sensemaking and organizational performance: Linkages among scanning, interpretation, action, and outcomes. Academy of Management Journal, 36, 239-270. 
Weick, K.E. (1995). Sensemaking in organizations. Thousand Oaks, CA: Sage.

Weitzel, W. \& Jonsson, E. (1989). Decline in organizations: A literature integration and extension. Administrative Science Quarterly, 34, 91-109.

Scott D. Julian is an assistant professor of management at Saginaw Valley State University. He received his Ph.D. from Louisiana State University. His current research interests involve interpretive and process issues associated with strategic control, the performance consequences of organizational certification/accreditation, and the strategic implications of diversity in organizations.

EIton Scifres is an associate professor of management at Stephen F. Austin State University. He received his Ph.D. from Louisiana State University. In addition to strategic control, his current research interests are in the areas of management education and the application of multiple perspectives to managerial problem solving. 
